\title{
Correction to: A variant of relaxed alternating positive semi-definite splitting preconditioner for double saddle point problems
}

\author{
Lingsheng Meng ${ }^{1} \cdot J^{\prime} \mathrm{Li}^{1} \cdot$ Shu-Xin Miao ${ }^{1}$
}

Published online: 18 May 2021

(C) The JIAM Publishing Committee and Springer Japan KK, part of Springer Nature 2021

\section{Correction to: Japan Journal of Industrial and Applied Mathematics https://doi.org/10.1007/s13160-021-00467-x}

In the original publication the article, the running head is published wrongly. The correct running head is "A VRAPSS preconditioner for double saddle point problems".

Publisher's Note Springer Nature remains neutral with regard to jurisdictional claims in published maps and institutional affiliations.

The original article can be found online at https://doi.org/10.1007/s13160-021-00467-x.

Jun Li

junli026430@163.com

1 College of Mathematics and Statistics, Northwest Normal University, Lanzhou 730070,

People's Republic of China 